\title{
Intensification of tropical cyclones in the GFS model
}

\author{
J. C. Marín ${ }^{1}$, D. J. Raymond ${ }^{2}$, and G. B. Raga ${ }^{1}$ \\ ${ }^{1}$ Centro de Ciencias de la Atmósfera, UNAM, Mexico City, Mexico \\ ${ }^{2}$ Physics Department, New Mexico Tech., Socorro, USA
}

Received: 21 July 2008 - Published in Atmos. Chem. Phys. Discuss.: 30 September 2008

Revised: 26 January 2009 - Accepted: 9 February 2009 - Published: 20 February 2009

\begin{abstract}
Special forecasts from the Global Forecast System (GFS) model were used in this study to evaluate how the intensification process in a tropical cyclone is represented in this model. Several tropical cyclones that developed in 2005 were analyzed in terms of the storm-scale circulation rather than more traditional measures such as maximum wind or minimum central pressure. The primary balance governing the circulation in the planetary boundary layer is between the convergence of environmental vorticity, which tends to spin up the storm, and surface friction, which tends to spin it down. In addition, we employ recently developed ideas about the relationship between precipitation and the saturation fraction of the environment to understand the factors controlling mass, and hence vorticity convergence. The budget of moist entropy is central to this analysis.

Two well-known governing factors for cyclone intensification emerge from this study; surface moist entropy fluxes, dependent in the model on sea surface temperature and cyclonegenerated surface winds, and ventilation of the system by dry environmental air. Quantitative expressions for the role of these factors in cyclone intensification are presented in this paper.
\end{abstract}

\section{Introduction}

The ability of numerical models to correctly simulate tropical cyclones has increased over time as a result of improved data assimilation techniques and observational platforms, a better representation of the physical processes and an increase in computational resolution. Tropical cyclone track forecasts have shown an appreciable improvement over the past decades (Burpee et al., 1996; Aberson, 2001; Rogers et

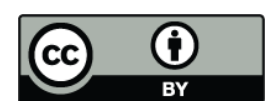

Correspondence to: J. C. Marín (juliocma@atmosfera.unam.mx) al., 2006); however, a much smaller reduction of the tropical cyclone intensity forecast errors has been observed (Elsberry et al., 1992; Marks and Shay, 1998; DeMaria et al., 2005; Rogers et al., 2006). Many factors contribute to the difficulty of an accurate tropical cyclone intensity forecast. Among them, is the incomplete understanding of the physical processes that favor tropical cyclone development. In spite of this, the Global Forecast System (GFS) model of NOAA/NCEP (National Oceanic and Atmospheric Administration/National Centers for Environmental Prediction) is beginning to make useful tropical cyclone forecasts.

The influence of the ocean on formation and intensification has been extensively studied for many years. Palmén (1948) found that tropical cyclones only originate when sea surface temperatures (SST) are larger than $26^{\circ} \mathrm{C}$. This was one of the necessary conditions recognized by Gray (1968) for tropical cyclogenesis. (Emanuel, 1986, 1989) and Rotunno and Emanuel (1987) hypothesized that tropical cyclones are maintained against dissipation through the energy supplied by entropy fluxes from the sea surface. Hurricane Opal (1995), for instance, showed a rapid intensification when it traversed a warm core eddy in the Gulf of Mexico associated with high oceanic heat content (Hong et al., 2000; Shay et al., 2000).

The presence of a large-scale low-level cyclonic circulation, the formation of cyclones north of $5^{\circ} \mathrm{N}$ and low tropospheric shear values $\left(<10-15 \mathrm{~ms}^{-1}\right)$ in the $850-200 \mathrm{hPa}$ layer are also necessary conditions for cyclogenesis (Gray, 1968). McBride and Zehr (1981) and Zehr (1992) showed that weak vertical wind shear, large cyclonic relative vorticity at lower levels and anticyclonic circulation at upper levels were the most important characteristics distinguishing developing from nondeveloping tropical cyclone precursors. Simpson and Riehl (1958) first pointed out that ventilation of low entropy air through the tropical cyclone at mid levels decreased its intensity, explaining why vertical wind shear can affect intensification. Other observational and numerical

Published by Copernicus Publications on behalf of the European Geosciences Union. 
studies (Gray, 1968; Knaff and Weaver, 2000; Emanuel et al., 2004) have also mentioned this mechanism as a strong inhibitor of cyclone development. Another negative effect of vertical shear on cyclone development is induced convective asymmetries (Elsberry et al., 1992; Corbosiero and Molinari, 2002, 2003; Black et al., 2002; Frank and Ritchie, $1999,2001)$. Intensification is also affected by the inward eddy flux of angular momentum at upper levels (Challa and Pfeffer, 1980; Pfeffer and Challa, 1981; Challa et al., 1998) and the interaction with an upper-level trough (Riehl, 1948; Molinari and Vollaro, 1989; Molinari et al., 1995; Hanley et al., 2001).

Results from the GFS model have been used by the National Hurricane Center (NHC) for several years to predict the track of tropical cyclones that develop over the Atlantic and the East Pacific basins; in addition, the model is showing some ability to predict tropical cyclogenesis and intensity change. We believe that it is valuable to determine the factors which control genesis and intensity in the GFS model; this exercise should be particularly useful in formulating hypotheses about how tropical cyclogenesis occurs in nature, thus suggesting what should be sought in observational programs.

Since the resolution of the GFS is coarse with respect to the inner core and rainband structure of an actual tropical cyclone, we cannot expect it to reproduce these fine details. Instead, we ask more modest questions about the larger scale structure of the storm. In particular, we define the intensity as the storm-scale circulation around the system rather than in terms of more traditional measures such as maximum wind or minimum central pressure.

The dynamical and thermodynamical mechanisms that determine whether a tropical cyclone will develop into a hurricane or not are investigated following the ideas of Raymond et al. (1998) and Raymond et al. (2007). Raymond et al. (1998) showed that the circulation tendency in the planetary boundary layer (PBL) around a tropical cyclone depends primarily on the imbalance between the convergence of absolute vorticity into the system and the Reynolds stress due to surface friction, the former causing spinup and the latter spindown. This imbalance governs cyclone spinup and spindown in the real world, and presumably in the GFS model. In line with current ideas about the production of precipitation and the associated latent heat release, we show that the convergence of absolute vorticity in the PBL, which is closely related to the mass convergence there, is strongly controlled in the model by the surface moist entropy fluxes and the ventilation of the system by dry environmental air.

Section 2 summarizes the basic characteristics of the GFS model, describes the methodology used to study the different tropical cyclone cases, and explains the theoretical aspects considered. Results and conclusions are shown in Sects. 3 and 4 , respectively.

\section{Data and methodology}

\subsection{The GFS model}

GFS is the global numerical weather prediction model run by NCEP four times per day to generate forecasts up to 16 days in advance. It consists of a forecasting model and the Global Data Assimilation System (GDAS), which provides the initial meteorological state through a three-Dimensional Variational (3-D Var) Gridpoint Statistical Interpolation (GSI) technique (NCEP Office Note 446). GFS is a global spectral model with a triangular spectral horizontal coordinate truncated after wavenumber 382 and a hybrid sigma-pressure vertical coordinate implemented with 64 levels. The horizontal resolution is approximately equivalent to a global $35 \mathrm{~km}$ mesh and the vertical domain extends from $997.3 \mathrm{hPa}$ to $0.266 \mathrm{hPa}$ for a surface pressure of $1000 \mathrm{hPa}$. A transformation to a Gaussian grid for calculation of nonlinear quantities and physics is made in the model. A complete description of the dynamical properties and the physical parametrizations included in the model can be found at the NCEP Office Note 442.

Forecast output from the GFS model was obtained for the period June-July 2005 but only the first $24 \mathrm{~h}$ forecasts were considered for each day. The reason for this choice is to allow the modeled fields to come into equilibrium with model physics while not letting the storm track and intensity deviate too much from reality. Results include traditional fields at 37 vertical pressure levels (wind components, temperature, relative humidity, specific humidity, geopotential, etc.) from 1000 to $100 \mathrm{hPa}$ and at the surface $(10-\mathrm{m}$ wind components, $2-\mathrm{m}$ relative humidity, temperature and specific humidity, surface fluxes, etc.) at a horizontal resolution of $1^{\circ} \times 1^{\circ}$. Two tropical storms that developed in the East Pacific and three hurricanes that developed in the Atlantic basin were chosen for this study (Fig. 1). They were analyzed in a $4^{\circ} \times 4^{\circ}$ square box centered on each system, which was identified from the surface wind field. The analysis included the calculation of several dynamical and thermodynamical terms that will be described below. The cyclones were studied from the time they became tropical depressions until they either reached maximum intensity as hurricanes or they dissipated. In the cases of tropical storms Eugene and Beatriz, 12 and $36 \mathrm{~h}$ before the time they reached the tropical depression stage were included in the study.

\subsection{Theoretical considerations}

The dynamical and thermodynamical aspects considered in the study, based on the ideas of Raymond et al. (1998) and Raymond et al. (2007) are applied to several tropical cyclones using forecast fields from the GFS model. 


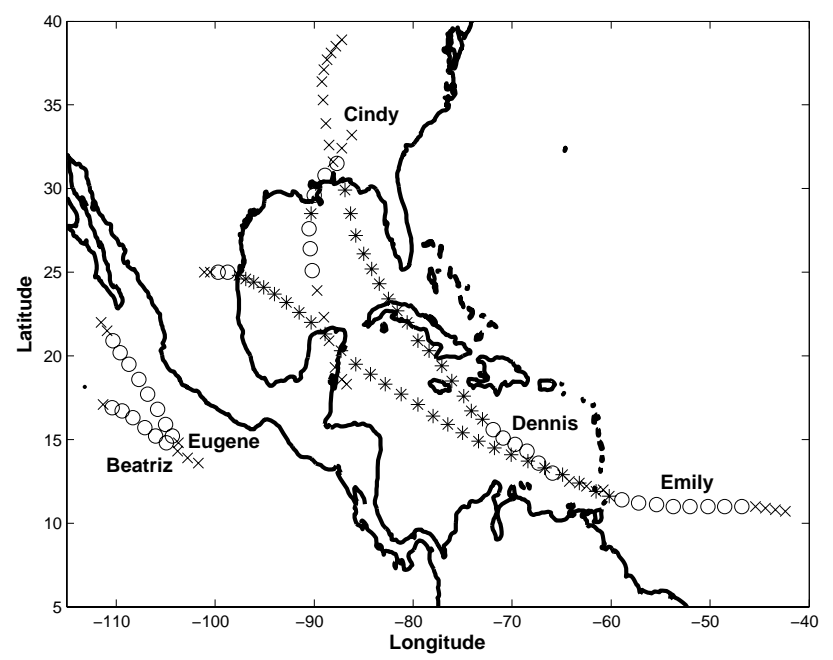

Fig. 1. Tracks of tropical cyclones studied. The tropical depression, tropical storm and hurricane stages are represented by crosses, open circles and stars, respectively.

\subsubsection{Dynamical aspects}

The vorticity equation in pressure coordinates was formulated in flux form by Haynes and McIntyre (1987):

$\frac{\partial \zeta_{a}}{\partial t}+\frac{\partial Z_{x}}{\partial x}+\frac{\partial Z_{y}}{\partial y}=0$

where $Z_{x}$ and $Z_{y}$ have the following form:

$Z_{x}=u \zeta_{a}+\omega \frac{\partial v}{\partial p}-F_{y}$

$Z_{y}=v \zeta_{a}-\omega \frac{\partial u}{\partial p}+F_{x}$

$\omega$ is the pressure vertical velocity, $p$ is pressure, $\zeta_{a}$ is the absolute vorticity, $\mathrm{u}$ and $\mathrm{v}$ are the wind components and $F_{x}$ and $F_{y}$ represent the horizontal components of the force due to the divergence of eddy momentum fluxes $\boldsymbol{F}=\left(F_{x}, F_{y}, 0\right)$. Using the relation $\nabla \cdot(\hat{\boldsymbol{k}} \times \boldsymbol{B})=-\hat{\boldsymbol{k}} \cdot(\nabla \times \boldsymbol{B})$, Eq. (1) can be written as:

$\frac{\partial \zeta_{a}}{\partial t}+\nabla \cdot \boldsymbol{Z}=\frac{\partial \zeta_{a}}{\partial t}+\nabla \cdot \boldsymbol{u} \zeta_{a}-\hat{\boldsymbol{k}} \cdot \nabla \times \boldsymbol{F}+\hat{\boldsymbol{k}} \cdot \nabla \times \omega \frac{\partial \boldsymbol{u}}{\partial p}$

$\boldsymbol{u}=(u, v)$ is the horizontal wind velocity and $\boldsymbol{Z}=\left(Z_{x}, Z_{y}\right)$. If Eq. (4) is integrated over a $4^{\circ} \times 4^{\circ}$ area that encompasses the cyclone area at all levels (Fig. 2), and the divergence and Stokes theorems and the relation

$\frac{d \Gamma_{a}^{*}}{d t}=\frac{d}{d t}\left(\int_{A} \zeta_{a} d A\right)$

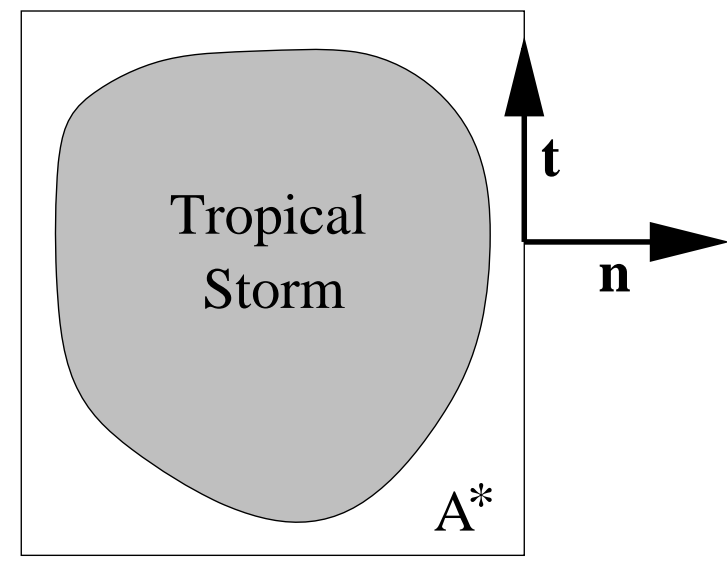

Fig. 2. Schematic representation of the tropical cyclone area (gray) and the area $A^{*}$ where calculations are made at each pressure level. Vectors $\boldsymbol{n}$ and $\boldsymbol{t}$ are normal and tangential vectors to the periphery of $A^{*}$.

are applied (* refers to the $4^{\circ} \times 4^{\circ}$ area), the following equation is obtained:

$\frac{d \Gamma_{a}^{*}}{d t}=-\oint_{\delta A^{*}} \zeta_{a} u_{\mathrm{out}} d s-\oint_{\delta A^{*}} \omega \frac{\partial \boldsymbol{u}}{\partial p} \cdot \boldsymbol{t} d s+\oint_{\delta A^{*}} \boldsymbol{F} \cdot \boldsymbol{t} d s(6)$

where $\Gamma_{a}^{*}$ is the absolute circulation, $\mathrm{u}_{\mathrm{out}}=\boldsymbol{u} \cdot \boldsymbol{n}$ and $\mathrm{u}_{\mathrm{tan}}=\boldsymbol{u} \cdot \boldsymbol{t}$ (used below) are the normal and tangential components of the wind $(\boldsymbol{u})$ to the area element $\delta A^{*}$ over the study area $A^{*}$, and $\boldsymbol{t}$ and $\boldsymbol{n}$ are unit vectors (Fig. 2). Equation (6) shows that the spinup of the tropical cyclone (positive absolute circulation tendency) depends on the convergence of the absolute vorticity into the system at each level and the line integral of vertical advection of momentum and of friction around area $A^{*}$.

The absolute circulation, the detrained $\left(\Delta^{*}\right)$ and vertical $\left(M^{*}\right)$ mass fluxes are calculated from the following expressions:

$$
\begin{aligned}
& \Gamma_{a}^{*}=\oint_{\delta A^{*}} \mathrm{u}_{\mathrm{tan}} d s+A^{*} f=\int_{A^{*}}\left(\frac{\partial v}{\partial x}-\frac{\partial u}{\partial y}\right) d A+A^{*} f \\
& \triangle^{*}=\oint_{\delta A^{*}} \mathrm{u}_{\mathrm{out}} d s=\int_{A^{*}}\left(\frac{\partial u}{\partial x}+\frac{\partial v}{\partial y}\right) d A \\
& M^{*}(z)=-\int_{0}^{z} \rho \Delta^{*} d z
\end{aligned}
$$

where $f$ is the Coriolis parameter and $\rho$ is the air density.

The force per unit mass $\boldsymbol{F}$ in Eq. (6) is determined as the vertically averaged drag force per unit mass due to surface friction and is calculated with the bulk formula: $\boldsymbol{F}=-C_{D} u_{s} \boldsymbol{u}_{s} / d$. The bulk transfer coefficient $\left(C_{D}\right)$ is obtained as described in Appendix A. The parameter $d$ is the assumed boundary layer depth and $\boldsymbol{u}_{\boldsymbol{s}}$ is the wind speed at 
the surface. However, the depth over which friction is distributed in the model is not known. Therefore, this bulk friction should be considered an approximation in which we assume a $d=1 \mathrm{~km}$ boundary layer depth (approximately the 1000-900 hPa layer).

\subsubsection{Thermodynamic aspects}

The specific moist entropy $s$ (calculated from Emanuel, 1994) obeys the following equation in pressure coordinates:

$$
\frac{\partial s}{\partial t}+\nabla \cdot(\boldsymbol{u} s)+\frac{\partial(\omega s)}{\partial p}=S_{0}
$$

where $\boldsymbol{u}$ is the horizontal velocity relative to the possibly moving target of the budget analysis (such as a tropical cyclone), $\omega$ is the pressure vertical velocity, and $S_{0}$ is the entropy source term, containing the effects of surface fluxes, radiation flux divergence and irreversible generation. Mass continuity is given by:

$\nabla \cdot(\boldsymbol{u})+\frac{\partial \omega}{\partial p}=0$

If the equations are averaged over the area $A^{*}$ shown in Fig. 2 (indicated by angle brackets \langle\rangle ), the entropy equation becomes

$$
\frac{\partial\langle s\rangle}{\partial t}+\frac{1}{A^{*}} \oint \mathrm{s} \boldsymbol{u} \cdot \boldsymbol{n} d l+\frac{\partial\langle\omega s\rangle}{\partial p}=\left\langle S_{0}\right\rangle
$$

where the divergence theorem has been used. The moist entropy $s$ is now divided into two parts: $s=\bar{s}+s^{\prime}$ where $\bar{s}$ is the average of $\mathrm{s}$ around the loop at each pressure level and $s^{\prime}$ is the deviation from this average. Substituting $s$ into the integral of Eq. (12) results in:

$$
\frac{\partial\langle s\rangle}{\partial t}+\frac{\bar{s}}{A^{*}} \oint \boldsymbol{u} \cdot \boldsymbol{n} d l+\frac{1}{A^{*}} \oint \mathrm{s}^{\prime} \boldsymbol{u} \cdot \boldsymbol{n} d l+\frac{\partial\langle\omega s\rangle}{\partial p}=\left\langle S_{0}\right\rangle
$$

Using the mass continuity and the divergence equation, the second term in Eq. (13) can be written as:

$$
\frac{\bar{s}}{A^{*}} \oint \boldsymbol{u} \cdot \boldsymbol{n} d l=-\bar{s} \frac{\partial\langle\omega\rangle}{\partial p}=-\frac{\partial\langle\omega \bar{s}\rangle}{\partial p}+\langle\omega\rangle \frac{\partial \bar{s}}{\partial p}
$$

Substituting Eq. (14) into Eq. (13), it results in:

$$
\frac{\partial\langle s\rangle}{\partial t}+\langle\omega\rangle \frac{\partial \bar{s}}{\partial p}+\frac{1}{A^{*}} \oint s^{\prime} \boldsymbol{u} \cdot \boldsymbol{n} d l+\frac{\partial\left\langle\omega s^{\prime}\right\rangle}{\partial p}=\left\langle S_{0}\right\rangle
$$

Finally, Eq. (15) is integrated over the depth of the troposphere, indicating this by square brackets [ ]:

$$
\left[\frac{\partial\langle s\rangle}{\partial t}\right]=\left[-\langle\omega\rangle \frac{\partial \bar{s}}{\partial p}\right]+\left[-V_{s}\right]+\left[\left\langle S_{0}\right\rangle\right]
$$

$V_{s}$ is defined as the entropy ventilation:

$V_{s}=\frac{1}{A^{*}} \oint s^{\prime} \boldsymbol{u} \cdot \boldsymbol{n} d \boldsymbol{l}$
It has been assumed that $\left[\partial\left\langle\omega s^{\prime}\right\rangle / \partial p=0\right]$ since $\left\langle\omega s^{\prime}\right\rangle$ should be approximately zero at the surface and the tropopause.

The first term in Eq. (16) is the mean moist entropy tendency inside the volume defined by the line integral, the surface and the tropopause. The second term is the entropy tendency due to minus the vertical advection of entropy. The third term is minus the contribution to the entropy tendency by ventilation through the sides of the box. Vertical advection of entropy and the ventilation tendency will refer to terms $[-\langle\omega\rangle \partial \bar{s} / \partial p]$ and $\left[-V_{s}\right]$, respectively in Sect. 3.2. A negative ventilation tendency will correspond to the replacement of high entropy air inside the box by air with lower entropy.

In the original work of Simpson and Riehl (1958) the term ventilation referred to the lateral advection of low entropy air from the outside toward the interior of a tropical cyclone under the influence of vertical wind shear. In that case, the ventilation was probably the cause for the temperature decrease in the rain areas near the vortex, thus reducing the efficiency of the mass circulation from the sub-cloud layer in maintaining the cyclone, a process that occurs on scales of tens of $\mathrm{km}$. In the present study, the effect of ventilation is analyzed over a much larger scale, the study volume $\left(4^{\circ} \times 4^{\circ}\right.$ area from the surface to tropopause) enclosing the tropical cyclone, since the GFS model cannot represent accurately the eyewall and rainbands structure, evolution and their interaction with the larger-scale environment.

The surface entropy flux was calculated with the following bulk formula:

$F_{e s}=\left[\rho C_{D} U_{B L}\left(s_{s s}-s_{B L}\right)\right] g / \Delta p$

where $\rho$ is the air density, $C_{D}$ is the bulk transfer coefficient calculated from Appendix A, $U_{B L}$ and $s_{B L}$ are the wind speed and the specific moist entropy, respectively, averaged over the first two model levels (1000 and $975 \mathrm{hPa}$ ) and $s_{s s}$ is the saturated specific entropy at the sea surface temperature (SST) and mean sea level pressure (MSLP). The entropy flux was divided by $\Delta p / g$ to obtain its average over the depth of the troposphere as expressed by Eq. (16), where $\Delta p$ is 900 $\mathrm{hPa}$ and $\mathrm{g}$ is the acceleration of gravity. The effects of radiation flux divergence and irreversible generation of entropy contained in the $\left[\left\langle S_{0}\right\rangle\right]$ term in Eq. (16) are not considered here.

\section{Results}

Results from the vorticity balance analysis for two tropical cyclone cases are described in Sect. 3.1: one that intensified and another that did not intensify into a hurricane. These cases are representative of all the cases analyzed. Results from the thermodynamic analysis are shown in Sect. 3.2. 

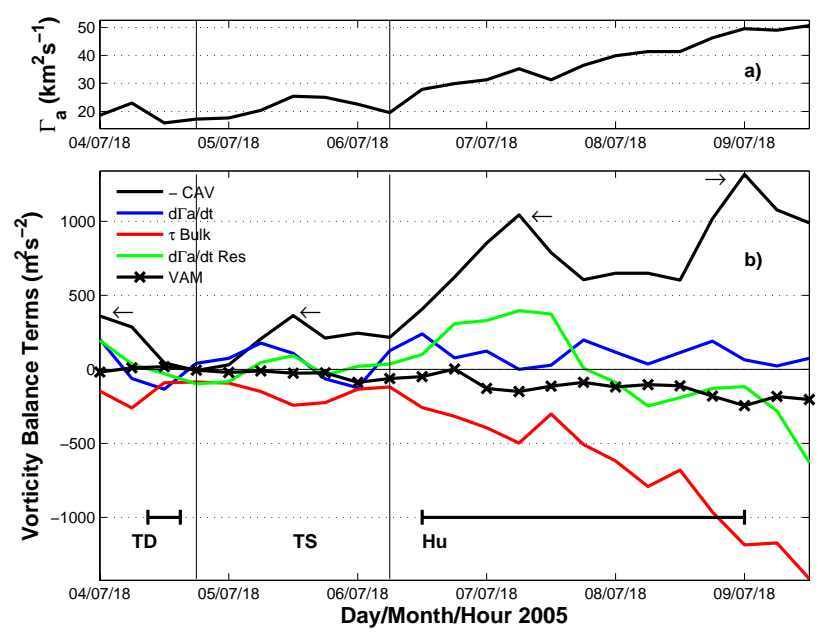

Fig. 3. Hurricane Dennis. (a) Time evolution of the absolute circulation averaged in the layer $1000-900 \mathrm{hPa}$. (b) Terms in the balance of Eq. (6) averaged in the layer 1000-900 hPa. The black line represents minus the convergence of absolute vorticity (-CAV), line with crosses (vertical advection of momentum, VAM), blue line ( $\Gamma_{a}$ tendency), red line (bulk friction term, $\tau$ Bulk) and green line (residual $\Gamma_{a}$ tendency). Vertical solid lines delimit the tropical depression (TD), tropical storm (TS) and hurricane (Hu) stages as determined by the NHC. Periods when Dennis made landfall are indicated by horizontal bars. Arrows indicate certain times that will be discussed in the text and in Figs. 7 and 8.

\subsection{Vorticity balance}

Equation (6), averaged over the $1000-900 \mathrm{hPa}$ layer, was analyzed for all cases. Figures 3 and 4 show this analysis for hurricane Dennis, which developed in the Caribbean region, and tropical storm Eugene which formed in the East Pacific. Vertical solid lines show the times when cyclones reach their different development stages, obtained from the NHC archives.

The circulation tendencies due to the convergence of absolute vorticity and to friction (related to the sub-grid scale turbulent momentum transfer due to deep convective and atmospheric boundary layer processes) are, in general, larger than the tendency due to the vertical advection of momentum; nonetheless, the influence of the latter cannot be neglected, specifically in intensifying tropical cyclones. The convergence of absolute vorticity causes the cyclones to intensify, while friction and vertical advection of momentum tend to decrease their intensity. Therefore, a positive $\Gamma_{a}$ tendency is observed when convergence of absolute vorticity is larger than the sum of those two negative terms.

Intensification in Dennis and Eugene is accompanied by a marked increase in convergence of absolute vorticity in the PBL, which is larger in the hurricane than in the tropical storm stage (Figs. 3 and 4). This is mainly the result of an increase in the horizontal mass flux into the cyclones, as Figs. 5
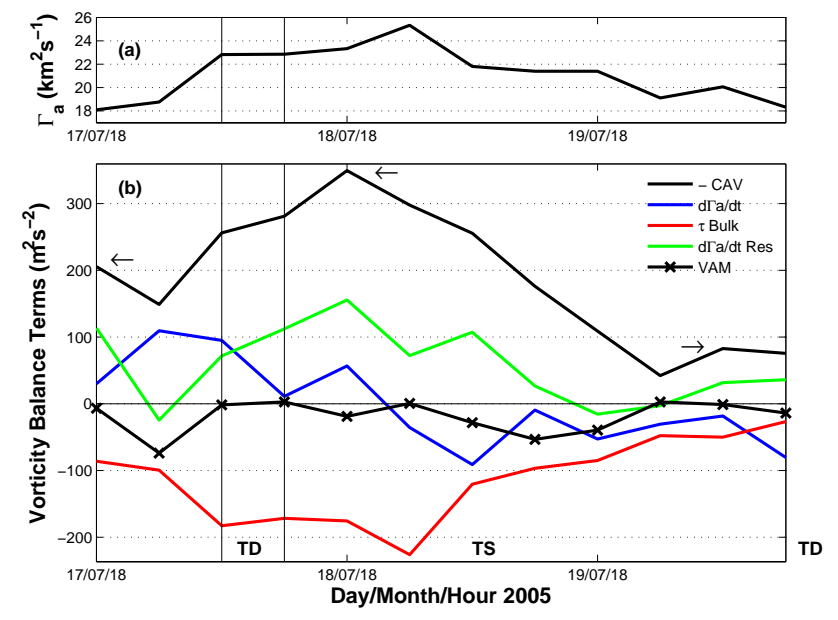

Fig. 4. Same as Fig. 3 but for tropical storm Eugene. Vertical solid lines delimit the tropical depression (TD) and tropical storm (TS) stages. Arrows indicate certain times that will be discussed in the text and in Figs. 9 and 10.

and 6 show. However, the absolute vorticity at the cyclone's boundary can significantly exceed the value of the Coriolis parameter. This factor is therefore responsible for some part of the spinup in many cases. In both Dennis and Eugene the convergence of vorticity is nearly in balance with the effects of surface friction and the vertical advection of momentum. The net spinup tendency is thus typically a small residual in the circulation equation. This is in agreement with the order of magnitude of the observed time rate of change of circulation. Due to the uncertainties in how the Reynolds stress divergence associated with surface friction is distributed vertically in the model and other factors, we can not expect the calculated residual circulation tendency to reflect in detail the actual change in circulation of the system with time.

Figure 7a shows the vertical profiles of convergence of absolute vorticity at four stages during the evolution of Dennis (indicated by the horizontal arrows in Fig. 3). The intensification from the tropical depression to the hurricane stage is characterized by a large increase in vorticity convergence at low levels partly as a result of an increase in the horizontal mass inflow there (Fig. 8) and partly due to an increase in the absolute vorticity of the air being ingested. Corresponding to this is a lowering of the level of the maximum vertical mass flux, a phenomenon observed in actual tropical cyclones (Raymond et al., 1998).

Three times (indicated by arrows in Fig. 4) were analyzed in the evolution of Eugene. The intensification to tropical storm category shows an increase in convergence of absolute vorticity at low levels for the first day, with maximum values in the layer 1000-900 hPa (Fig. 9a). However, the vorticity convergence decreases drastically thereafter as the system decays. Thus, as with Dennis and the other systems, 


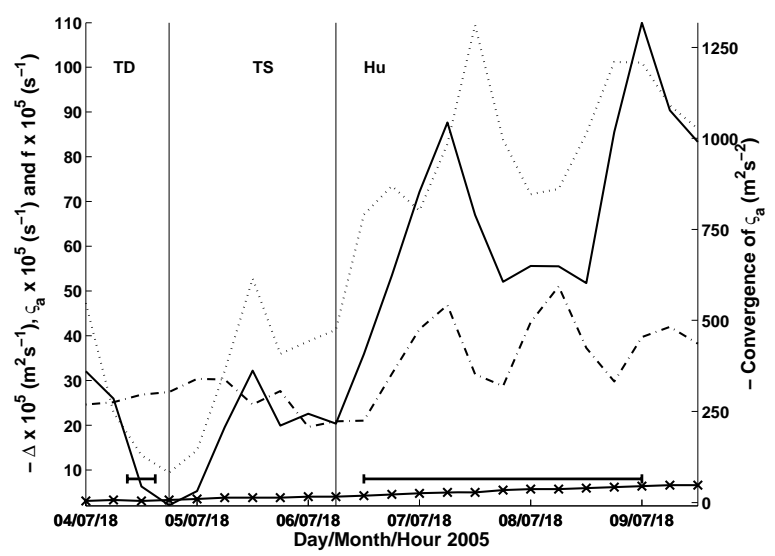

Fig. 5. Time evolution of minus the convergence of absolute vorticity (solid line), $-\triangle$ (dotted line), and the absolute vorticity at the cyclone's boundary $\left(s_{a}\right)$ (dashed-dotted line) averaged over the 1000$900 \mathrm{hPa}$ for hurricane Dennis. The line with crosses represents the Coriolis parameter at Dennis's central latitude. The absolute vorticity and Coriolis were multiplied by 4 for a better comparison with the other variables. Vertical solid lines delimit the tropical depression (TD), tropical storm (TS) and hurricane (Hu) stages. Periods when Dennis made landfalling are indicated by horizontal bars.

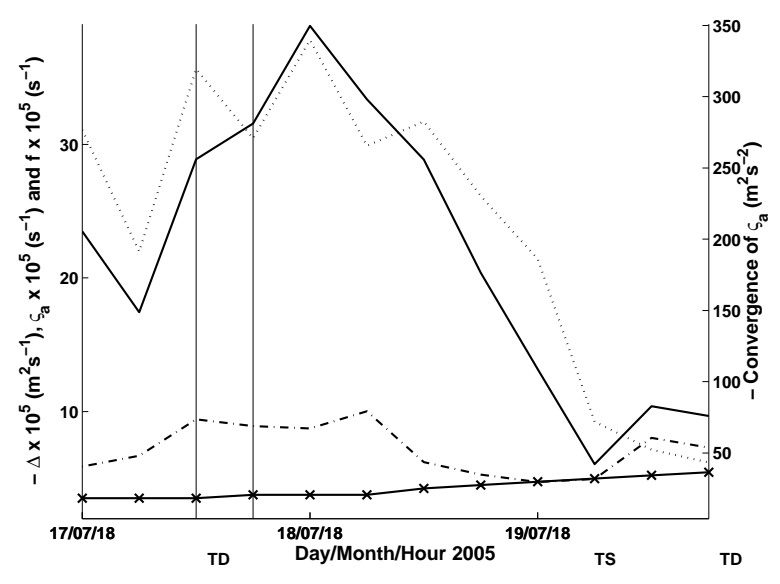

Fig. 6. Time evolution of minus the convergence of absolute vorticity (solid line), $-\triangle$ (dotted line), and the absolute vorticity at the cyclone's boundary $\left(\varsigma_{a}\right)$ (dashed-dotted line) averaged over the $1000-900 \mathrm{hPa}$ for tropical storm Eugene. The line with crosses represents the Coriolis parameter at Eugene's central latitude. Vertical solid lines delimit the transition from tropical depression (TD) to tropical storm (TS).

intensification is intimately related to the convergence of vorticity in the GFS. We now examine the factors controlling this convergence.
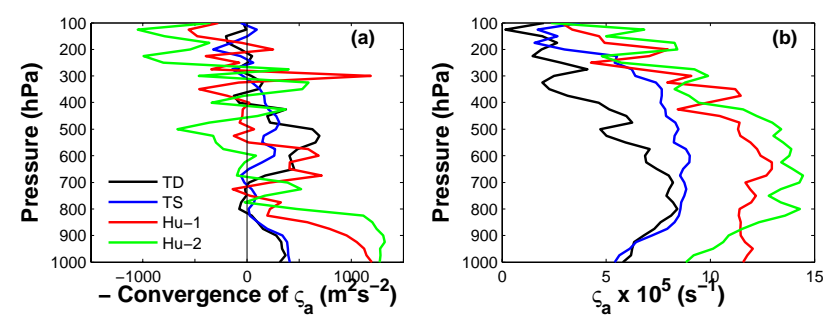

Fig. 7. Vertical profiles of (a) minus the convergence of absolute vorticity and (b) absolute vorticity at the cyclone's boundary averaged over the $4^{\circ} \times 4^{\circ}$ area at four times during hurricane Dennis' life cycle. Tropical depression time (TD, black line), tropical storm time (TS, blue line), first hurricane time (Hu-1, red line) and second hurricane time (Hu-2, green line).
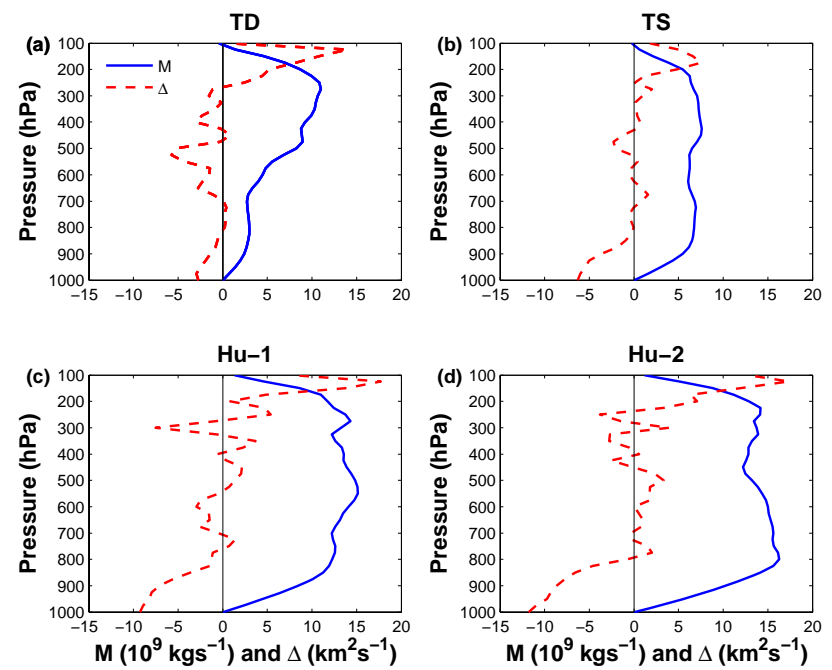

Fig. 8. Vertical profiles of horizontal ( $\Delta$, red dashed line) and vertical ( $M$, blue solid line) mass fluxes for hurricane Dennis at (a) the tropical depression time (TD), (b) the tropical storm time (TS), (c) the first hurricane time (Hu-1) and (d) the second hurricane time (Hu-2) analyzed.

\subsection{Entropy balance}

In order to gain a better understanding of the processes that cause some systems to intensify into a hurricane and others not to intensify, the thermodynamic analysis described in Sect. 2.2 is applied below to the five cases studied.

\subsubsection{Hurricane Dennis}

With minor exception, the circulation in the PBL around the numerically simulated Atlantic hurricane Dennis increases monotonically through the entire period considered, as Fig. 11 shows. For most of the period the SST exceeds $28.5^{\circ} \mathrm{C}$ and for the first three days the ventilation tendency is 

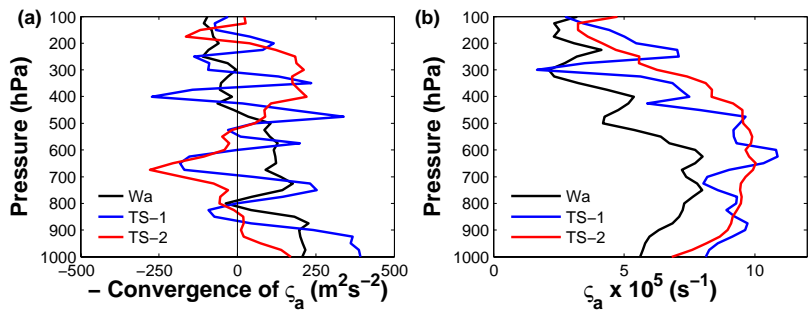

Fig. 9. Vertical profiles of (a) minus the convergence of absolute vorticity and (b) absolute vorticity at the cyclone's boundary averaged over the $4^{\circ} \times 4^{\circ}$ area at three times during tropical storm Eugene's life cycle. Tropical wave time (Wa, black line), first tropical storm time (TS-1, blue line) and second tropical storm time (TS-2, red line) before it decayed back to tropical depression stage.

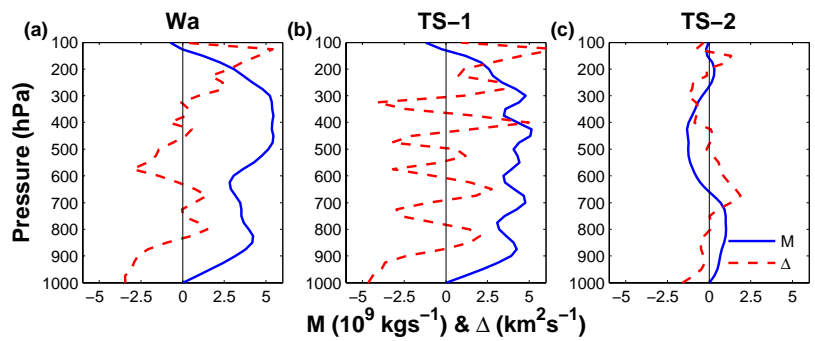

Fig. 10. Vertical profiles of horizontal ( $\Delta$, red dashed line) and vertical $(M$, blue solid line) mass fluxes for tropical storm Eugene at (a) the tropical wave time (Wa), (b) the first tropical storm time (TS1) and (c) the second tropical storm time (TS-2), before it decayed back to tropical depression stage.

near zero, with mostly weak negative values thereafter. The surface entropy flux increases in step with the circulation, as does the average moist entropy within the system. The entropy tendency due to vertical advection is negative for most of the period, with a magnitude generally somewhat less than the tendency due to surface entropy fluxes. Thus, surface entropy fluxes are high, ventilation is minimal, and Dennis intensifies into a major hurricane.

\subsubsection{Tropical storm Eugene}

In contrast, the circulation around East Pacific tropical storm Eugene (see Fig. 12) increases until shortly after it attains tropical storm category and decreases thereafter. The ventilation tendency is near zero up to the time of peak circulation and exhibits increasingly negative episodes thereafter. However, the most important factor in the decay of the simulated Eugene is likely to be the drastic decrease in SST which commences just after the time of peak circulation. The entropy tendency due to vertical advection is negative up to the time of maximum circulation, gradually changing to positive thereafter. Mean entropy peaks at the time of maximum circulation.

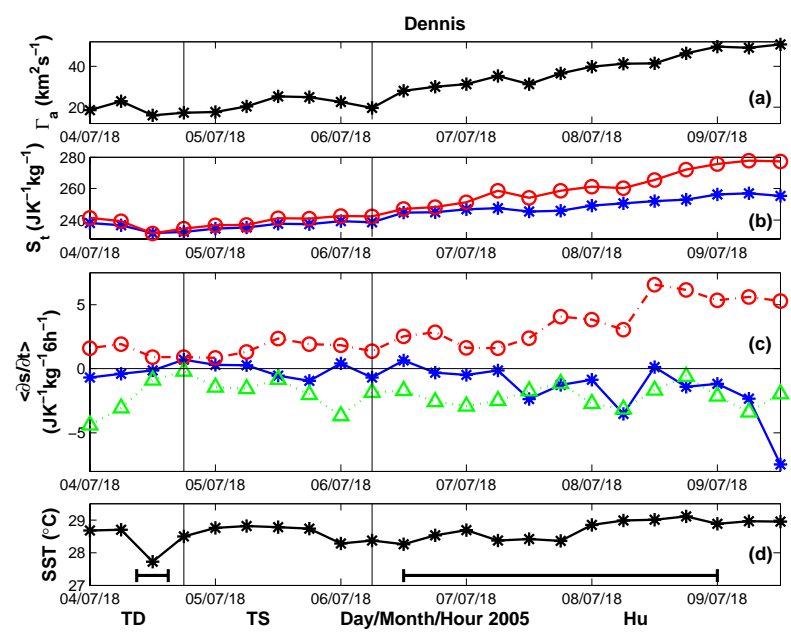

Fig. 11. Temporal distribution of (a) $\Gamma_{a}$ averaged in the layer 1000$900 \mathrm{hPa}$, (b) entropy averaged over the $4^{\circ} \times 4^{\circ}$ domain (star) and entropy at the cyclone's center (open circle), both averaged over the depth of the troposphere $(1000-100 \mathrm{hPa})$, (c) entropy tendency due to ventilation (star) and vertical advection of entropy (triangle) averaged over the 1000-100 hPa layer and the surface entropy flux (open circle) averaged over the inner points of the $4^{\circ} \times 4^{\circ}$ domain, and (d) SST averaged over the $4^{\circ} \times 4^{\circ}$ domain for hurricane Dennis. Vertical solid lines delimit the tropical depression (TD), tropical storm (TS) and hurricane (Hu) stages. Periods when Dennis made landfall are indicated by horizontal bars.

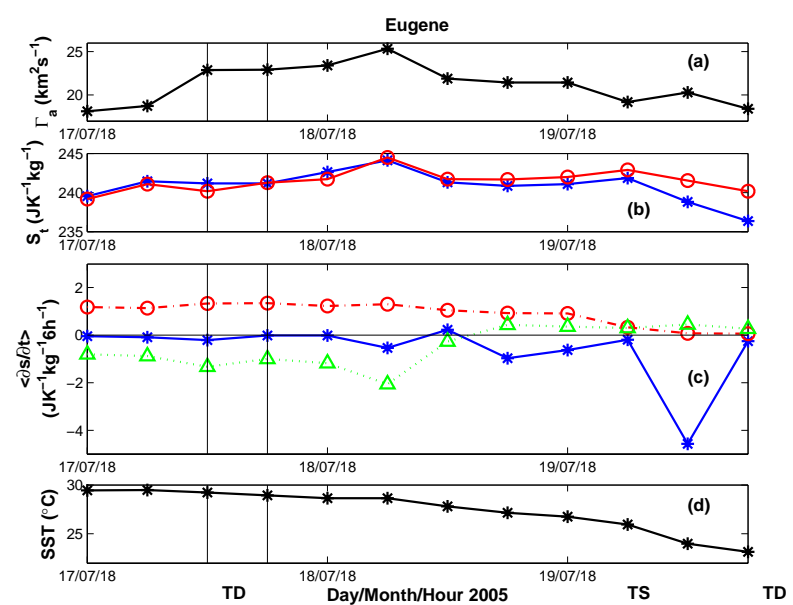

Fig. 12. Same as Fig. 11 but for tropical storm Eugene. Vertical solid lines delimit the tropical depression (TD) and tropical storm (TS) stages.

\subsubsection{Tropical storm Beatriz}

East Pacific tropical storm Beatriz presents a more complex case in that both ventilation and reduced SSTs appear to play an important role in its development and decay. For the first 


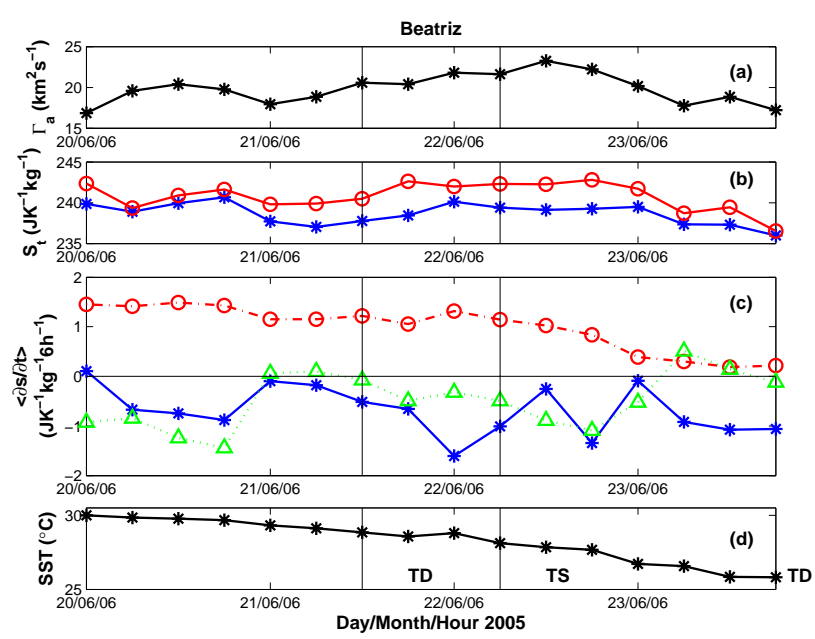

Fig. 13. Same as Fig. 11 but for tropical storm Beatriz. Vertical solid lines delimit the tropical depression (TD) and tropical storm (TS) stages.

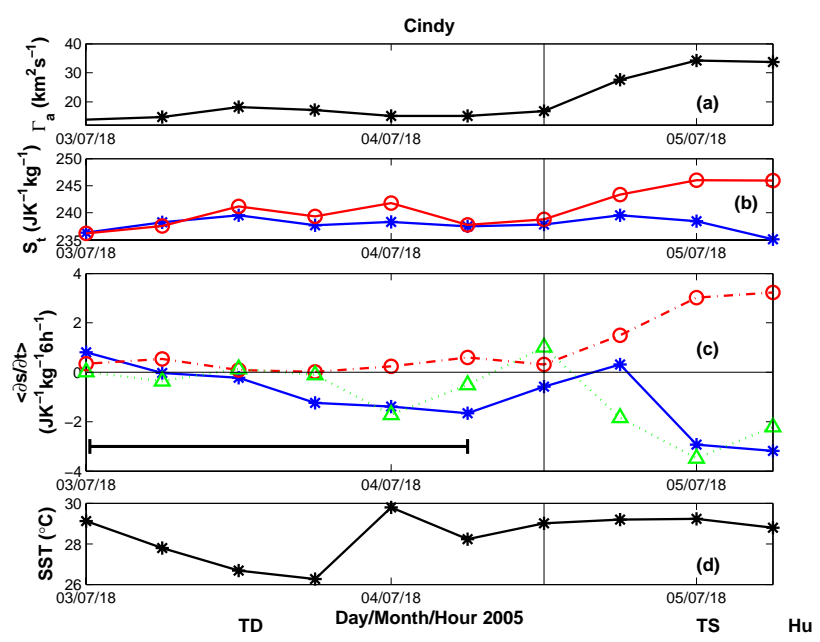

Fig. 14. Same as Fig. 11 but for hurricane Cindy. Periods when Cindy made landfalling are indicated by horizontal bars.

two days presented in Fig. 13 the SST experienced by Beatriz in the model exceeds $28^{\circ} \mathrm{C}$. However, the circulation only increases when the ventilation is weak near the very beginning of the first day and most of the second day. After the second day more rapidly decreasing SSTs and episodes of strong ventilation are correlated with decreasing PBL circulation. The decreasing SSTs correspond to strongly decreasing surface entropy fluxes during this latter phase.

\subsubsection{Hurricane Cindy}

Atlantic hurricane Cindy is also affected by both strong SST variations and variations in ventilation in the model. Exami-

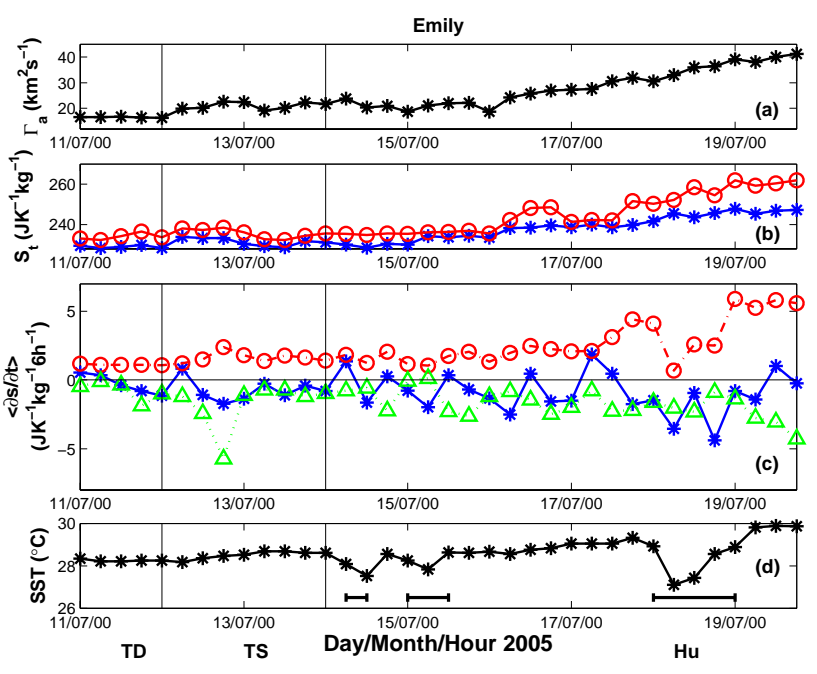

Fig. 15. Same as Fig. 11 but for hurricane Emily. Periods when Emily made landfalling are indicated by horizontal bars.

nation of Fig. 14 shows that Cindy fails to intensify when either SST values are low or ventilation tendencies are strongly negative, or both. Only during the second day displayed in this figure when SSTs exceed $29^{\circ} \mathrm{C}$ and the ventilation relaxes for a short period does the storm circulation increase significantly. This case illustrates in particular the powerful effect of ventilation in limiting intensification, even in the presence of high SSTs.

\subsubsection{Hurricane Emily}

Atlantic hurricane Emily shows an evolution which is rather similar to that of Dennis (Fig. 15). SSTs generally exceed $28^{\circ} \mathrm{C}$ except for some minor episodes, increasing to $30^{\circ} \mathrm{C}$ near the end of the period studied. Ventilation is slightly stronger than for Dennis, but significantly weaker than for Beatriz and Cindy. Strengthening of the circulation is slow for the first couple of days, but it then accelerates as Emily intensifies into a major hurricane. The entropy tendency associated with vertical advection fluctuates, but is generally negative over the period studied.

\section{Discussion and conclusions}

Forecast output from the GFS model was used in this study to investigate the different atmospheric mechanisms that favor the intensification of tropical cyclones into hurricanes and those responsible for halting intensification. Several cases were analyzed based on the vorticity and entropy balance equations, corroborating the strong influence of sea-air entropy fluxes and ventilation by environmental air on tropical cyclones. In addition, quantitative measures of the influence of these factors are introduced. 
The convergence of absolute vorticity favors the intensification while friction and vertical advection of momentum act to decrease it in the GFS model. Intensification is accompanied by a large increase in convergence of absolute vorticity at low and mid-levels, which is the result of strong horizontal mass inflow and large absolute vorticity at the cyclone boundary. Unfortunately, our diagnostic methods are insufficiently accurate to show quantitatively that vorticity convergence exceeds friction and vertical momentum advection during intensification and the opposite during dissipation; these terms are typically close to balance with the actual circulation tendency being a small residual, but there is little doubt that this is occurring. The small value of the circulation tendency relative to the other terms indicates that the modeled systems remain very close to Ekman balance throughout their simulated life cycles.

Convergence of absolute vorticity and horizontal mass inflow in the model concentrate in a shallower layer as a tropical cyclone intensifies. As a result, the level of nondivergence and peak vertical mass flux decrease in height. The absolute vorticity at the cyclone's boundary increases at all heights with intensification.

The theoretical analysis of Raymond et al. (2007) highlights the key role played by precipitation in the intensification of tropical cyclones. Precipitation is associated with latent heat release which is most intense in the lower troposphere. This in turn is correlated with ascending motion, and hence convergence in the lower troposphere.

Significant evidence has accumulated indicating that rainfall over tropical oceans is controlled to a large degree by the saturation fraction (precipitable water divided by saturated precipitable water) of the tropospheric column. In the tropics the temperature profile of the troposphere varies minimally, which means that the moist entropy profile is closely related to the saturation fraction. We analyze the moist entropy budget for this reason.

Following Neelin and Held (1987) and Raymond (2000), we note that the time tendency of moist entropy in the troposphere has terms related to the surface entropy flux, the radiative loss of entropy at the tropopause, and the lateral import or export of entropy. The last can be split into two terms, a part associated with the vertical advection of entropy in the troposphere and a part associated with the horizontal advection of environmental air through the cyclone, which we call the ventilation tendency. The first term is closely related to Neelin and Held's gross moist stability (GMS).

The vertical advection tendency is generally positive when ascent is concentrated in the lower troposphere where the vertical gradient of environmental moist entropy is negative, whereas it is negative when ascent is concentrated in the upper troposphere where the gradient is positive. In the former case the GMS is negative, in the latter it is positive according to Neelin and Held's definition. Examination of Figs. 11 through 15 suggests that the vertical advection tendency is negative when a cyclone is intensifying, but tends to zero or slightly positive $6-12 \mathrm{~h}$ after decay commences. This suggests that a transition from deep to shallow (but still precipitating) convection occurs when a cyclone begins to decay.

The two external environmental factors which affect the moist entropy budget in the model are the SST, which enters into the sea-air entropy fluxes, and the environmental wind profile measured relative to the moving cyclone, which drives the ventilation. The vertical entropy advection tendency also has a large effect on the entropy budget within the cyclone, but is presumably a response to environmental factors rather than an environmental driver itself. Examination of Figs. 1115 suggests that these two environmental factors can indeed explain the behavior of the five modeled cyclones:

- Dennis and Emily experience high SSTs and weak ventilation compared to sea-air moist entropy fluxes throughout the intervals considered, and both amplify into major hurricanes.

- For the first day Eugene intensifies under the influence of high SSTs and weak ventilation. Subsequently SSTs decrease dramatically and ventilation progressively strengthens. Simultaneously intensification stops and decay sets in.

- Beatriz experiences high SSTs for the first two days but is episodically subjected to moderate to strong ventilation relative to the computed surface entropy fluxes. Episodes of intensification appear to be related to periods in which ventilation relaxes. After $2.5 \mathrm{~d}$ decay sets in, probably as a result of diminishing surface entropy fluxes associated with decreasing SSTs.

- Cindy remains weak for $1.5 \mathrm{~d}$ in conjunction with a period of low SSTs and ventilation which is strong relative to surface entropy fluxes. Only when this ventilation decreases in magnitude does Cindy intensify.

That low SST and strong ventilation by environmental air appear to be the primary factors inhibiting tropical cyclone intensification will come as no surprise. However, two points make these results worth reporting: (1) We have documented this behavior in NCEP's GFS model, which is one of the principal models used by cyclone forecasters around the world. (2) Casting these factors in terms of tendencies in the moist entropy budget equation allows the importance of these factors to be evaluated quantitatively rather than on an ad-hoc basis. Hopefully this diagnostic tool can be extended to other models and to the real world in the study of tropical cyclone behavior.

\section{Appendix A}

Figure 16 shows drag coefficient estimates as a function of neutral wind speed at $10 \mathrm{~m}$ from several recent studies, modified from Fig. 5 in Black et al. (2007). The COARE 3.0 


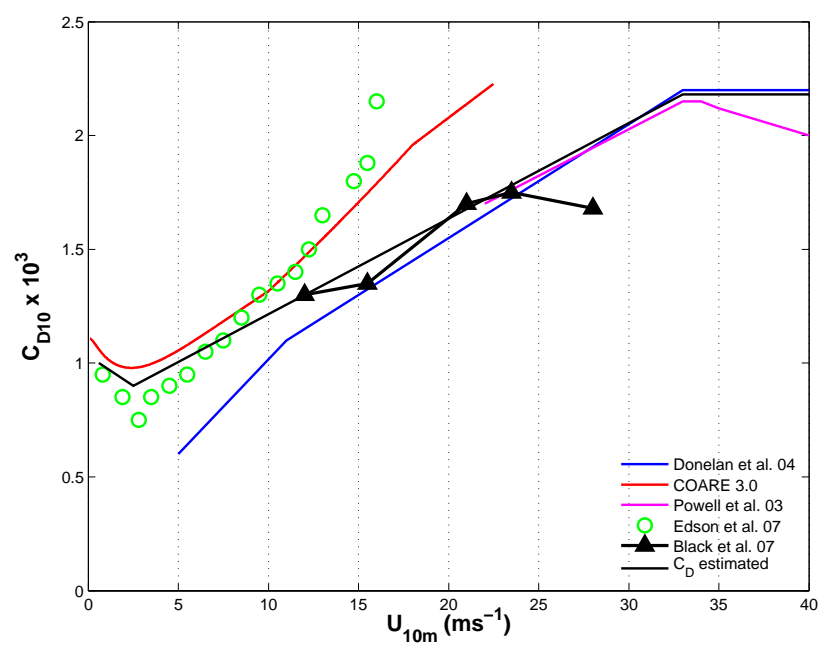

Fig. 16. Drag coefficient estimates as a function of the $10 \mathrm{~m}$ neutral wind from the several recent studies shown in the legend. The black solid line shows the $C_{D}$ obtained from them for this study.

(Fairall et al., 2003) and Edson et al. (2007) estimations were obtained for open-sea conditions from low to moderate wind speed regimes $\left(0-20 \mathrm{~ms}^{-1}\right)$ and show a good agreement between them. A drop in $C_{D}$ with the increase in wind speed is observed for very low wind values, characteristic of a smooth aerodynamical surface becoming rougher for wind speeds larger than $3 \mathrm{~ms}^{-1}$ with the corresponding increase in $C_{D}$. Other studies have focused on the $C_{D}$ behavior under strong wind speed conditions, relevant to tropical storms and hurricanes (Powell et al., 2003; Donelan et al., 2004; Black et al., 2007). The fundamental result from these studies is that $C_{D}$ stops increasing at a specific wind speed value and it behaves nearly constant for larger wind speeds. A threshold value of approximately $33 \mathrm{~ms}^{-1}$ is obtained by Donelan et al. (2004) and Powell et al. (2003) using laboratory measurements and wind sonde profiles inside storms, respectively. A lower threshold value of near $23 \mathrm{~ms}^{-1}$ is estimated by Black et al. (2007) from CBLAST (Coupled Boundary Layer AirSea Transfer) in-situ measurements inside hurricanes in the Atlantic ocean.

Wind speed values from GFS forecasts range from near zero to approximately $40 \mathrm{~ms}^{-1}$ for the different tropical cyclones analyzed. A piecewise estimate of $C_{D}$ as a function of wind speed was obtained graphically from Fig. 16 (solid line) and used to estimate the bulk fluxes in this study:

$$
\begin{aligned}
& C_{D 10 \mathrm{~m}}=\left[-0.053 u_{10 \mathrm{~m}}+1.03\right] \cdot 10^{-3} \\
& \text { for } 0 \leq u_{10 \mathrm{~m}}<2.5 \mathrm{~ms}^{-1} \\
& C_{D 10 \mathrm{~m}}=\left[0.042 u_{10 \mathrm{~m}}+0.8\right] \cdot 10^{-3} \\
& \text { for } 2.5 \mathrm{~ms}^{-1} \leq u_{10 \mathrm{~m}}<33 \mathrm{~ms}^{-1} \\
& C_{D 10 \mathrm{~m}}=2.18 \cdot 10^{-3} \\
& \text { for } 33 \mathrm{~ms}^{-1} \leq u_{10 \mathrm{~m}}<40 \mathrm{~ms}^{-1}
\end{aligned}
$$

Acknowledgements. This work was carried out with the aid of a grant from the Inter-American Institute for Global Change Research (IAI) CRN II \# 2048 which is supported by the US National Science Foundation (Grant GEO-0452325). JCM acknowledges support by a scholarship from the Dirección General de Estudios de Posgrado, UNAM. DJR was supported by US National Science Foundation Grant ATM-0352639.

Edited by: T. Karl

\section{References}

Aberson, S. D.: The ensemble of tropical cyclone track forecasting models in the North Atlantic Basin (1976-2000), B. Am. Meteorol. Soc., 82, 1895-1904, 2001.

Black, M. L., Gamache, J. F., Marck Jr., F. D., Samsury, C. E., and Willoughby, H. E.: Eastern Pacific hurricanes Jimena of 1991 and Olivia of 1994: The effect of vertical shear on structure and intensity, Mon. Weather Rev., 130, 2291-2312, 2002.

Black, P. G., D'Asaro, E. A., Drennan, W. M., French, J. R., Niiler, P. P., Sanford, T. B., Terrill, E. J., Walsh, E. J., and Zhang, J. A.: Air-sea exchange in hurricanes: synthesis of observations from the Coupled Boundary Layer Air-Sea Transfer Experiment, B. Am. Meteorol. Soc., 88, 357-374, 2007.

Burpee, R. W., Aberson, S. D., Franklin, J. L., Lord, S. J., and Tuleya, R. E.: The impact of omega dropwindsondes on operational hurricane track forecast models, B. Am. Meteorol. Soc., 77, 925933, 1996.

Challa, M. and Pfeffer, R. L.: Effects of eddy fluxes of angular momentum on model hurricane development, J. Atmos. Sci., 37, 1603-1618, 1980.

Challa M., Pfeffer, R. L., Zhao, Q., and Chang, S. W.: Can eddy fluxes serve as a catalyst for hurricane and typhoon formation? J. Atmos. Sci., 55, 2201-2219, 1998.

Corbosiero, K. L. and Molinari, J.: The effects of vertical wind shear on the distribution of convection in tropical cyclones, Mon. Weather Rev., 130, 2110-2123, 2002.

Corbosiero, K. L. and Molinari, J.: The relationship between storm motion, vertical wind shear, and convective asymmetries in tropical cyclones, J. Atmos. Sci., 60, 366-460, 2003.

DeMaria, M., Mainelli, M., Shay, L. K., Knaff, J. A., and Kaplan, J.: Further improvements to the Statistical Hurricane Intensity Prediction Scheme (SHIPS), Weather Forecast., 20, 531-543, 2005.

Donelan, M. A., Haus, B. K., Reul, N., Plant, W. J., Stianssnie, M., Graber, H. C., Brown, O. B., and Saltzman, E. S.: On the limiting aerodynamic roughness of the ocean in very strong winds, Geophys. Res. Lett., 31, L18306, doi:10.1029/2004GL019460, 2004.

Edson, J., Crawford, T., Crescenti, J., Farrar, T., Frew, N., Gerbi, G., Helmis, C., Hristov, T., Khelif, D., Jessup, A., Jonsson, H., Li, M., Mahrt, L., McGillis, W., Plueddemann, A., Shen, L., Skyllingstad, E., Stanton, T., Sullivan, P., Sun, J., Trowbridge, J., Vickers, D., Wang, S., Wang, Q., Weller, R., Wilkin, J., Williams, A.J., Yue, D.K.P., and Zappa, C.,: The Coupled Boundary Layers and Air-Sea Transfer experiment in low winds, B. Am. Meteorol. Soc., 88, 341-356, 2007.

Elsberry, R. L., Emanuel, K. A., Holland, G., Gerrish, H., DeMaria, M., and Guard, C.: Is there any hope for tropical cyclone inten- 
sity prediction? A panel discussion, B. Am. Meteorol. Soc., 73, 264-275, 1992.

Emanuel, K. A.: An air-sea interaction theory for tropical cyclones. Part I, J. Atmos. Sci. 42, 1062-71, 1986.

Emanuel, K. A.: The finite-amplitude nature of tropical cyclogenesis, J. Atmos. Sci., 46, 3431-56, 1989.

Emanuel, K. A.: Atmospheric convection, Oxford University Press, 580 pp., 1994.

Emanuel, K., DesAutels, C., Holloway, C., and Korty, R.: Environmental control of tropical cyclone intensity, J. Atmos. Sci., 61, 843-858, 2004.

Fairall, C. W., Bradley, E. F., Hare, J. E., Grachev, A. A., and Edson, J. B.: Bulk parameterization of air-sea fluxes: Updates and verification for the COARE algorithm, J. Climate, 16, 571-591, 2003.

Frank, W. M. and Ritchie, E. A.: Effects of environmental flow upon tropical cyclone structure, Mon. Weather Rev., 127, 2044-2061, 1999.

Frank, W. M. and Ritchie, E. A.: Effects of vertical wind shear on the intensity and structure of numerically simulated hurricanes, Mon. Weather Rev., 129, 2249-2269, 2001.

Global Climate \& Weather Modeling Branch, EMC.: The GFS atmospheric model, NCEP Office Note 442, 14 pp., 2003.

Global Climate \& Weather Modeling Branch, EMC.: Near-surface data assimilation in the NCEP Gridpoint Statistical-Interpolation System: Use of land temperature data and a comprehensive forward model, NCEP Office Note 446, 46 pp., 2005.

Gray, W. M.: Global view of the origin of tropical disturbances and storms, Mon. Weather Rev., 96, 669-700, 1968.

Haynes, P. H. and McIntyre, M. E.: On the evolution of vorticity and potential vorticity in the presence of diabatic heating and frictional or other forces, J. Atmos. Sci., 44, 828-841, 1987.

Hanley D. E., Molinari, J., and Keyser, D.: A composite study of the interaction between tropical cyclones and upper-tropospheric troughs, Mon. Weather Rev., 129, 2570-2584, 2001.

Hong, X., Chang, S. W., Raman, S., Shay, L. K., and Hodur, R.: The interaction between hurricane Opal (1995) and a warm core ring in the Gulf of Mexico, Mon. Weather Rev., 128, 1347-1365, 2000.

Knaff, J. A. and Weaver, J. F.: A mesoscale low-level thunderstorm outflow boundary associated with hurricane Luis, Mon. Weather Rev., 128, 3352-3355, 2000.

Marks, F. D. and Shay, L. K.: Landfalling tropical cyclones: Forecast problems and associated research opportunities, B. Am. Meteorol. Soc., 79, 867-876, 1998.

McBride, J. L. and Zehr, R.: Observational analysis of tropical cyclone formation. Part II: Comparison of nondeveloping versus developing systems, J. Atmos. Sci., 38, 1132-1151, 1981.
Molinari, J. and Vollaro, D.: External influences on hurricane intensity. Part I: Outflow layer eddy angular momentum fluxes, J. Atmos. Sci., 46, 1093-1105, 1989.

Molinari, J., Skubis, S., and Vollaro, D.: External influences on hurricane intensity. Part III: Potential vorticity structure, J. Atmos. Sci., 52, 3593-3606, 1995.

Neelin, J. D. and Held, I. M.: Modeling tropical convergence based on the moist static energy budget, Mon. Weather Rev., 115, 3-12, 1987.

Palmén, E.: On the formation and structure of tropical hurricanes, Geophysica, 3, 26-39, 1948.

Pfeffer, R. L. and Challa, M.: A numerical study of the role of eddy fluxes of momentum in the development of Atlantic hurricanes, J. Atmos. Sci., 38, 2393-2398, 1981.

Powell, M. D., Vickery, P. J. and Reinhold, T. A.: Reduced drag coefficient for high wind speeds in tropical cyclones, Nature, 422, 279-283, 2003.

Raymond, D. J.: Thermodynamic control of tropical rainfall, Q. J. Roy. Meteor. Soc., 126, 889-898, 2000.

Raymond, D. J., Lopez-Carrillo, C. and Lopez, L.: Case-studies of developing East Pacific easterly waves, Q. J. Roy. Meteor. Soc., 124, 2005-2034, 1998.

Raymond, D. J., Sessions, S., and Fuchs, Z.: A theory for the spinup of tropical depressions, Q. J. Roy. Meteor. Soc., 133, 1743-1754, 2007.

Riehl, H.: On the formation of typhoons, J. Meteor., 5, 247-264, 1948.

Rogers, R., Aberson, S., Black, M., Black, P., Cione, J., Dodge, P., Dunion, J., Gamache, J., Kaplan, J., Powell, M., Shay, N., Surgi, N., and Uhlhorn, E.: The Intensity Forecasting Experiment: A NOAA multiyear field program for improving tropical cyclone intensity forecasts, B. Am. Meteorol. Soc., 87, 1523-1537, 2006.

Rotunno, R. and Emanuel, K. A.: An air-sea interaction theory for tropical cyclones - Part II, J. Atmos. Sci., 44, 542-61, 1987.

Shay, L. K., Goni, G. J., and Black, P. G.: Effects of warm oceanic feature on hurricane Opal, Mon. Weather Rev., 128, 1366-1383, 2000.

Simpson, R. H. and Riehl, H.: Mid-tropospheric ventilation as a constraint on hurricane development and maintenance, Proc. Tech. Conf. on Hurricanes, Miami Beach, FL, Amer. Meteor. Soc., D4-1-D4-10, 1958.

Zehr, R. M.: Tropical cyclogenesis in the Western North Pacific, NOAA technical report NESDIS 61, 181 pp. (Available from Dept. of Atmospheric Sciences, Colorado State University, Fort Collins, CO.), 1992. 